\title{
Considerations of Probability-Based Fatigue Design for Marine Structures
}

Pauf H. Wirsching, University of Arizona, Tucson, Arizona

Y.-N. Chen, American Bureau of Shipping, Paramus, New Jersey

ARSTRACT

Fatigue is a major failure mode in marine structures which respond dynamically to random wave and wind Toading. Oscillatory stresses produce fatigue at points of stress concentration, typically the welded joints. Because all fatigue design factors are subject to significant uncertainty, a reliability approach to management of such uncertainty seems appropriate. This article summarizes some studies in fatigue relianitity research and demonstrates how reliability methods can be effectively utilized by designers to avoid fatigue in marine structura? components. Includer are (1) a description of fatigue damage under variable amplitude stresses employing the characteristic $S-N$ and fracture mechanics models, (2) models for reliability assessment relative to fatigue and the use of these models to derive design criteria, and (3) an elementary application of system fatigue reliability analysis to establish component design criteria.

\section{INTRODUCTION}

In general, reliability methods seem particularly appropriate for application to the marine structure design process because of uncertainties in the ocean environment and the historical use of statistical descriptions of that environment. But, structural component strength (particularly fatigue) data have considerable scatter. Thus, both structural loads and capacities are subjected to uncertainty.

Summarized in this paper are considerations of reliability analysis to fatigue in marine structures. Specific goals of such anatyses are (1) reliability assessment of an existing or proposed designs and (2) development of fatigueavoidance criteria appropriate for inclusion in design criteria documents or codes. Demonstrated are how reliability methods can be used as an effective design tool. It is implicitly assumed herein that fatigue will occur at welded joints, but the models are generic and could apply to other details as weil.

Recommended as general references are the Fatigue Handbook [1] published as a Norwegian effort, an "encyclopedia" of tubular joint design by the British $[2]$, SSC-313 by Murse et al. [3], SSC -325 by Burnside et a1. [4], a paper by Marsiall and Luyties [5], and a book by Gurney [6].
FATIGUE STRENGTH: ELEMENTARY ENGINEERING MODELS

The characteristic S-N curve

$$
N S^{m}=A \quad S>0
$$

is commonly employed to describe fatigue strength of structural components, where $m$ and $A$, determined empirically from constant amplitude S-N data, are the fatigue strength exponent and fatigue strength coefficient, respectively. As an extension of this basic mode?, a more general two-segment $\mathrm{S}-\mathrm{N}$ curve as shown in Figure 1 reflects experimental data which tind to show an improvement in fatigue streng+1 at lower stresses.

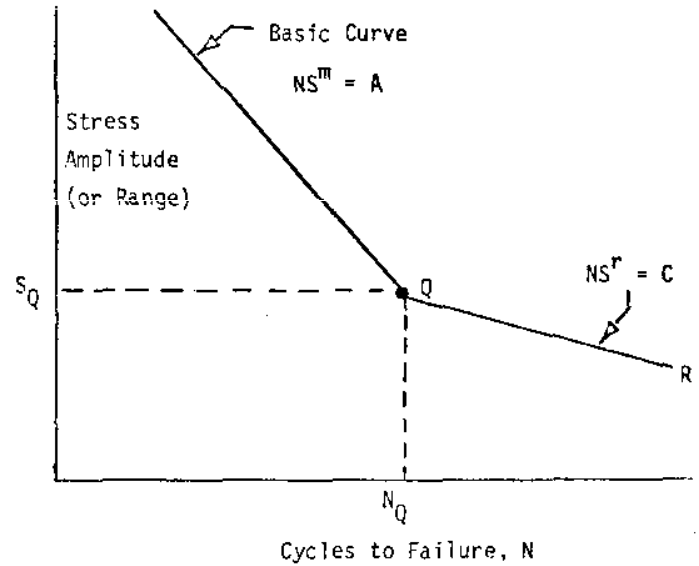

Fig. 1 Two-segment S-N curve

The fracture mechanics fatigue model is described in References [1], [2], and [7]. Assume that the crack propagation law is as defined in Figure 2. The Paris law is assumed to be valid for subcritical crack growth; $K_{c}$ is fracture toughness and $\Delta K_{t h}$ is the threshold stress intensity. Furthermore, we now assume that stress is a random process. Assuming an "equivalent stress" approach and after some analyses, it can be shown that [7]

$$
N=\frac{1}{c \overline{S^{m}}} \int_{a_{0}}^{a f} \frac{d a}{G(a) Y^{m}(a)(\pi a)^{1 / 2}},
$$

where $a=$ crack depth; $a_{0}$ and $a_{f}=$ initial crack 


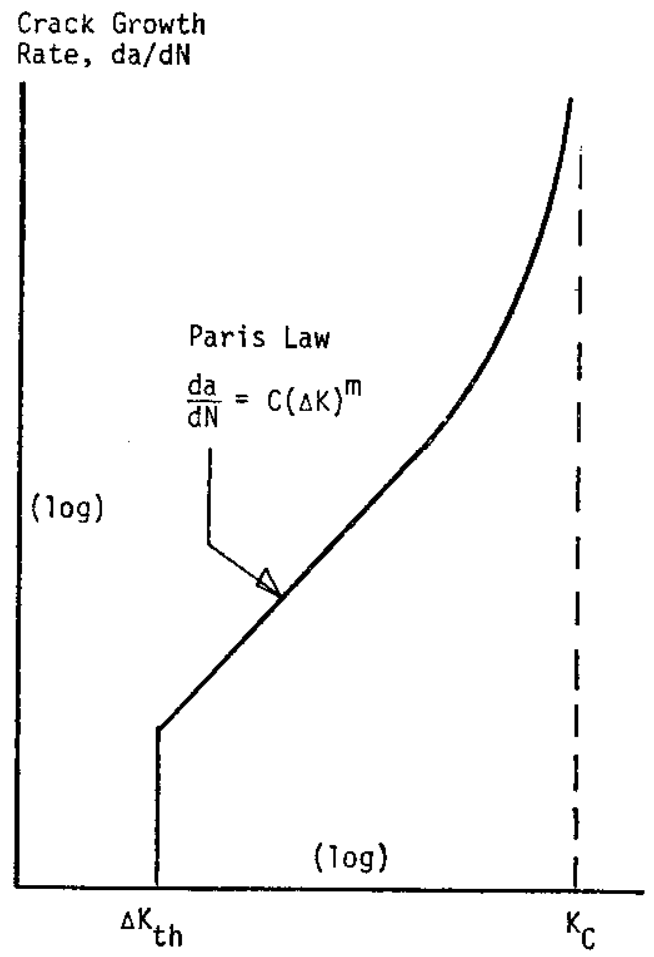

Range of Stress Intensity Factor, $\Delta \mathrm{K}$

Fig. 2 A model for fatigue crack growth

depth and crack depth at failure, respectively; $Y$ is the geometry factor; and

$$
\begin{gathered}
G(a)=\frac{\overline{s_{0}^{m}}(a)}{\overline{s^{m}}} \quad \overline{s^{m}}=E\left(S^{m}\right) \\
\overline{s_{0}^{m}}=\int_{s_{0}(a)}^{\infty} s^{m} f_{s}(s) d s \\
s_{0}(a)=\frac{\Delta K_{t h}}{Y(a) \sqrt{\pi a}} .
\end{gathered}
$$

By multiplying both sides of Eq. 2 by $\overline{S^{m}}$, the characteristic $S-N$ form of $E q .1, N \overline{S m}=A$, results; $\overline{S^{m}}=\left(S_{e}\right)^{m}$, where $S_{e}$ is equivalent stress and $A$ is a function of all of the parameters in the crack growth law. Thus, the fracture mechanics-based fatigue crack growth law can be cast in a characteristic $\mathrm{S}-\mathrm{N}$ format.

\section{FATIGUE DAMAGE UNDER VARIABLE AMPLITUDE LOADING}

Assuming that fatigue strength is defined by Eq. 1 and that Miner's rule works, fatigue damage $D$ can be written as

$$
D=\frac{n}{A} B^{m} E(S m) \text {, }
$$

where $S$ is a random variable denoting estimated stress range for a single cycle, $n$ is the total number of cycles applied, and $E(\cdot)$ is the expected value. $B$ is introduced as a bias factor on stress range in recognition that the actual stress differs from the estimated stress because of modeling error resulting from assumptions made in the stress analysis. The event of failure is defined as $D>1$.

It is convenient to write $D$ as

$$
D=\frac{T B^{m} \Omega}{A}
$$

where $T=n / f_{0}$ is time of exposure, $f_{0}$ is the lifetime average zero up-crossing frequency of the stress range, and $\Omega=f_{0} E(s m)$ is the stress parameter. Models which are routinely employed by the marine industry are summarized in Table I $[8,9]$.

The Weibull model for $S$ is commonly employed for a simplified fatigue assessment and for derivation of design criteria. The distribution function is

$$
F_{S}(s)=1-\exp \left[-\left(\frac{s}{\delta}\right)^{\xi}\right] \quad s>0 .
$$

where $\xi$ and $\delta$ are the Weibull shape and scale parameters, respectively. This model idealizes the long-term distribution of stress range.

By defining a "design" stress $S_{0}$ as

$$
P\left(S>S_{0}\right)=\frac{1}{N_{T}} \text {, }
$$

where $N_{T}$ is the total number of cycles in the service life, $S_{0}$ is then the value exceeded by $S$ on an average of once every $N_{T}$ times. The scale parameter $\delta$ can be written in terms of $S_{0}, \xi$, and $\mathrm{N}_{T}$ as

$$
\delta=S_{0}\left[\ln \mathrm{N}_{T}\right]^{-1 / \xi} .
$$

The Weibull distribution function is plotted in Figure 3 in a form useful for designers. A key role is played by the shape parameter which describes implicitly both the environment and the structural system $\xi$. Some typical values are $\xi=0.5$ for Gulf of Mexico platforms, $\xi=$ 0.5 to 0.7 for template platforms outside the Gulf without significant dynamic amplification, and $\xi=1.0$ for semi-submersibles and gravity platforms. Figure 4 (from Munse et al. [3]) shows $\xi=0.7$ to 1.3 for hull girder stresses in ships (which, as a warning, may not be directly related to the most troublesome fatigue failures in ship structures).

\section{FATIGUE DAMAGE: PIECEWISE LINEAR S-N CURVES}

Damage expressions of Eq. 4 and 5 depend upon the assumption that fatigue strength is defined by Eq. 1. But the two-segment $S-N$ curve of Figure 1, which provides an improvement in fatigue strength at lower stresses, is specified by API [10] and the UK DEn [11]. Extrapolation of $\mathrm{NS} M=\mathrm{A}$ into the high cycle range produces conservative results. Differences in damage estimates between the two-segment and linear 
Table I. A summary of the expressions for fatigue damage.

\begin{tabular}{|c|c|}
\hline & Fatigue Damage at Time $T$ \\
\hline \multicolumn{2}{|r|}{$D=T B^{m_{\Omega}} / A$} \\
\hline$m$, & $=$ parameters from $S-N$ curve (Eq. 1) \\
\hline B & $\begin{aligned}= & \text { factor to account for uncertainties in estimating fatigue } \\
& \text { stresses from oceanographic data }\end{aligned}$ \\
\hline$\Omega$ & $=f_{0} E\left(S^{m}\right)$, stress parameter \\
\hline
\end{tabular}

Stress Parameter Using Various Approaches

to the Stress Distribution

- Wave Exceedance Diagram (Deterministic Method)

$$
\begin{aligned}
\Omega & =f_{0} \zeta_{j} S_{i}^{m} \\
f_{0} & =\text { average frequency of stresses } \\
S_{i} & =\text { stress range } \\
\zeta_{i} & =\text { fraction of total stress ranges of } S_{i}
\end{aligned}
$$

- Spectral Method (Probabilistic Method)

$$
\begin{aligned}
\Omega & =\lambda(m)(2 \sqrt{2})^{m} \Gamma(m / 2+1) \sum_{i} \gamma_{j} f_{j} \sigma_{i} \\
\lambda(m) & =\text { rainflow correction }[8,9] \\
\Gamma(\cdot) & =\text { gamma function } \\
\gamma_{i} & =\text { fraction of time in } i^{\text {th }} \text { sea state } \\
f_{i} & =\text { frequency of wave loading in the } i \text { th sea state } \\
\sigma_{j} & =\text { RMS of stress process in the } i \text { th sea state }
\end{aligned}
$$

- Weibull Model for Stress Ranges

$$
\begin{array}{ll}
\Omega & =f_{0} S_{m}^{m}\left[\ln N_{T}\right]^{-m / \xi} \Gamma(m / \xi+1) \\
S_{m} & =\text { largest "once in a lifetime" stress range } \\
\xi & =\text { stress range parameter } \\
N_{T} & =\text { total number of stress ranges in design life }
\end{array}
$$

- Nolte-Hansford Model [39] (Extension of the Weibul1 Model)

$$
\Omega=\quad=f_{0} \delta^{m \phi} \psi^{m} \Gamma(m \phi / \xi+1)
$$

Terms same as Weibull except $\phi, \psi=$ parameters from empirical

equation $S=\psi H^{\phi}$, where $H$ is wave height 


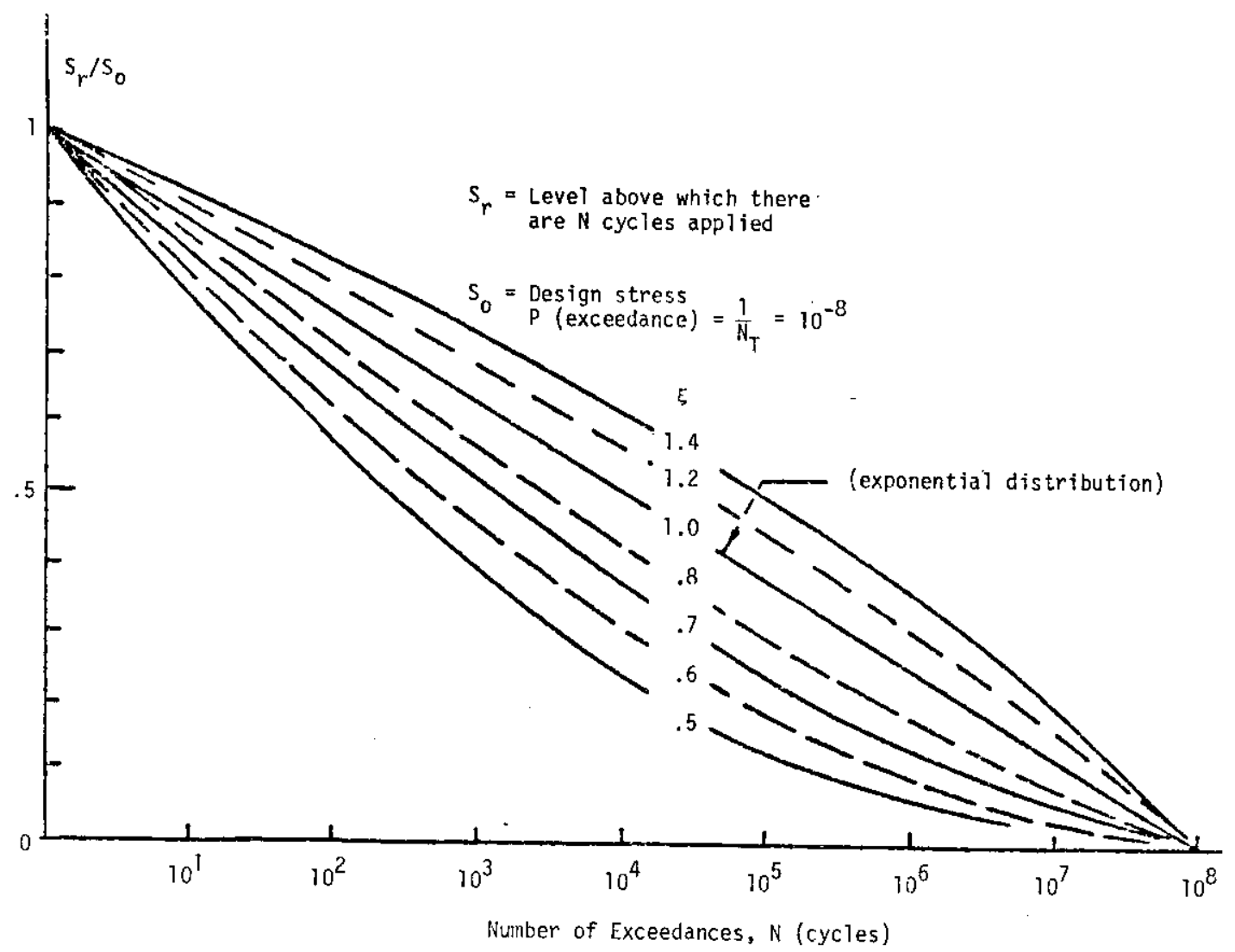

Fig. 3 Long-tern distribution of stress ranges; Weibull distribution function

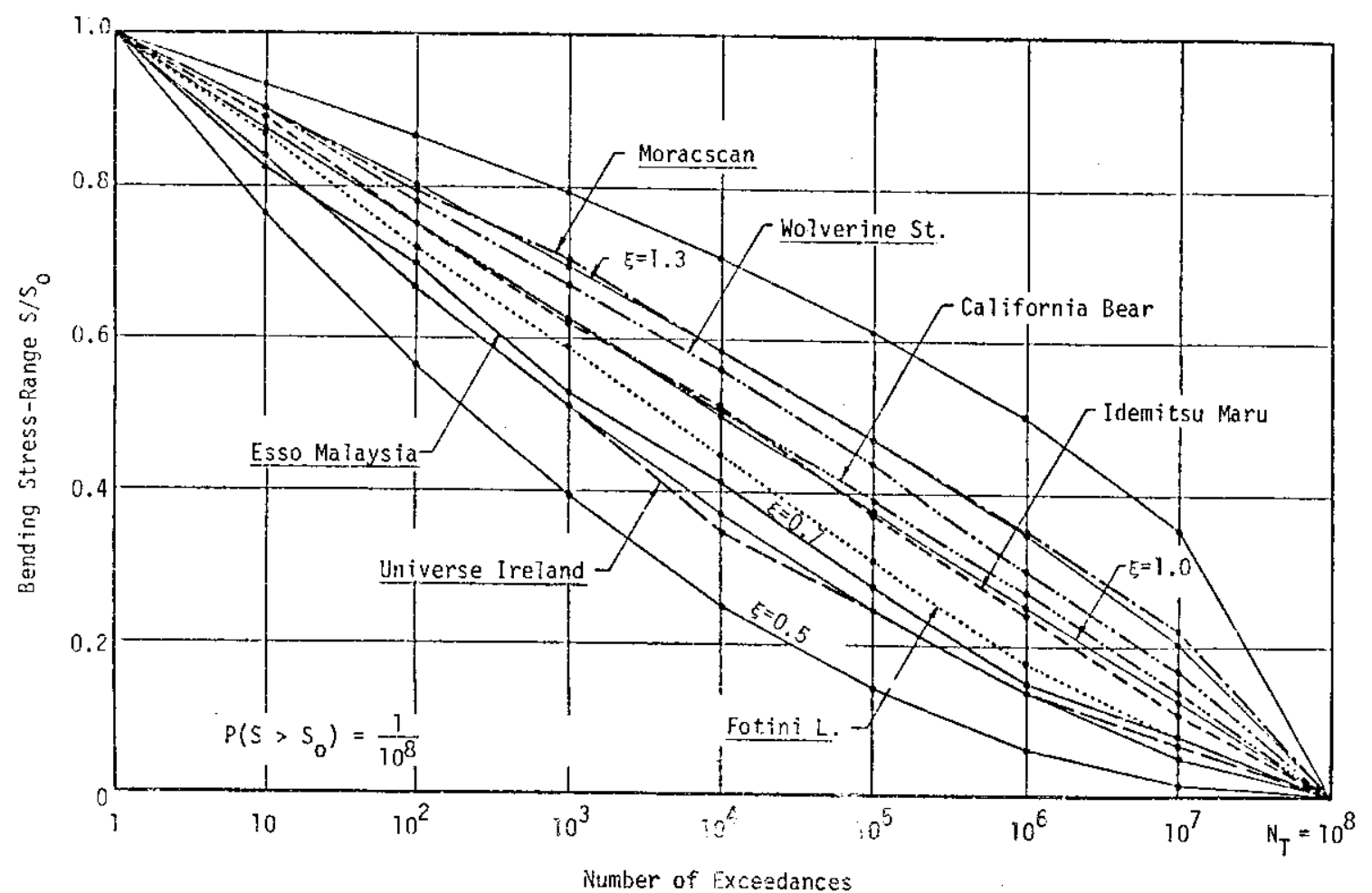

Fig. 4 Loading histories of large tankers, bulk carriers, and dry-cargo vessels compared with Weibull (after Munse [3]) 
cases were studied in an unpublished article [12] and are summarized as follows.

Assume that the long-term distribution of stress ranges, $S$, is Weibull (Eq. 6, 7, and 8). Given the form of Figure 1 , it $c$ an be shown that fatigue damage for the two-segment case is

$$
D_{B}=\Lambda D \text {, }
$$

where $\Lambda$ is the bias factor given as

$$
\Lambda=\frac{A \delta^{r-m} \Gamma_{0}(b, z)}{C \Gamma(a)}+\Psi(a, z)
$$

where

$$
\begin{array}{rlrl}
\Psi(a, z) & =\frac{\Gamma(a, z)}{\Gamma(a)}, & z=\left(S_{Q} / \delta\right)^{\xi}, \\
a & =\frac{m}{\xi}+1, & b & =\frac{r}{\xi}+1
\end{array}
$$

$\Gamma(x)$ is the gamma function, and $\Gamma(a, z)$ and $\Gamma_{0}(a$, $z$ ) are incomplete gamma functions (integrals $z$ to $\infty$ and 0 to $z$, respectively).

Two examples are presented in Figure 5 (bias factor for UK DEn-T curve) and Figure 6 (bios factor for API-X curve).
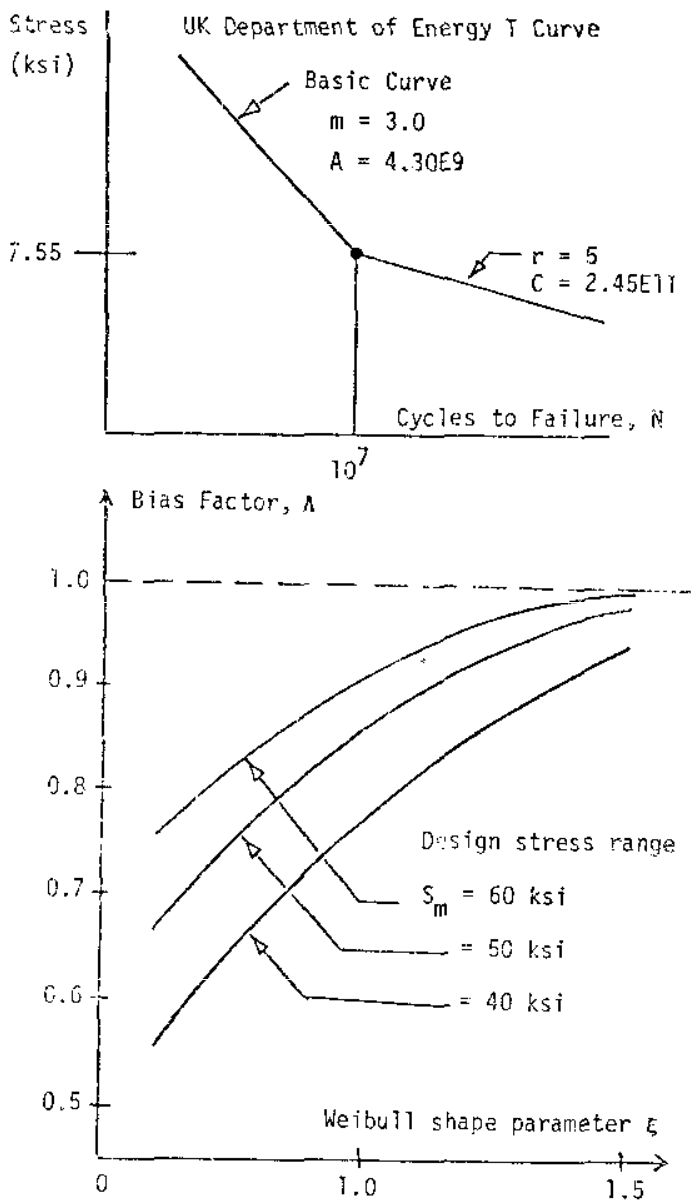

Fig. 5 Bias factor for DEn-T curve
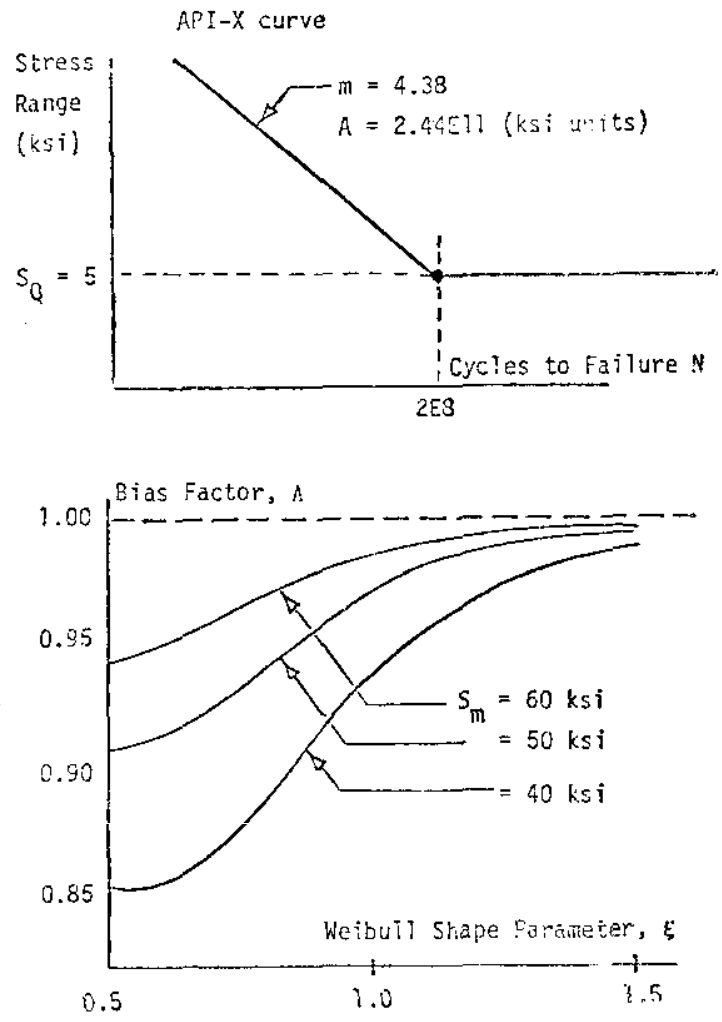

Fig. 6 Bias factor for API-X curve

In summary, it can be seen that for a welldesigned inint (i.e.. assumed to have $S_{0}=60$ $\mathrm{ksi}$, the reduction in damage implied by the endurance limit of the API-X curve is modest. On the other hand, reduction in damage from the linear case implied by the high cycle segment of the UK DEn-T curve can be as high as $20 \%$ for the same joint.

Described above were engineering models of fatigue. Now, attention will focus on the probability problem in which uncertainties in the fatigue analysis processes will be translated into random variables of the design factors in such a way to make reliability assessment tractable.

\section{FATIGUE RELIABILITY MODEL: SSC/MUNSE}

The model used by Munse et al. in SSC-318 [3] for reliability assessment relative to fatigue in a component was originally derived by Ang [13]. The development of this model is well documented $[3,13]$ and only a summary is provided here.

Let $\mathrm{N}$ be a random variable denoting cycles to failure. Assume that $\mathrm{N}$ has a Weihull distribution. The shape and scale parameters are

$$
\alpha=C_{N}^{-1.08} \quad \gamma=\frac{\mu_{N}}{\Gamma\left(\frac{1}{\alpha}+1\right)} \text {, }
$$


Where $y_{y}$ is the mean life obtained from a least squares analysis of fatigue data and $C_{N}$ is the coefficient of variation (COV) of cycle life. All uncertainty is included in $C_{N}$ :

$$
c_{N}=\left[c_{f}^{2}+m^{2} C_{S}^{2}+C_{C}\right]^{1 / 2},
$$

where all C's are Cov's. CS accounts for stress modeling error, $C_{C}$ for workmanship uncertainty, and $C_{f}=\sqrt{\delta_{f}^{2}+\Delta_{f}^{2}}$. $\quad \delta_{f}$ and $\Delta_{f}$ are Cov's repre-

senting scatter inherent in $\mathrm{S}-\mathrm{N}$ data and uncertainties in Miner's rule, respectively.

Miner's rule is assumed, which implies that $E\left(S^{m}\right)=A / \mu N$. Then it is easily shown that the probability of failure at the service life $\mathrm{N}_{S}$ is

$$
p_{f}=\left[\frac{N_{S} E(S m) \Gamma\left(1+C_{N}^{-1.08}\right)}{A}\right]^{C_{N}^{-1.08}} .
$$

The use of this form to derive design criteria is demonstrated below.

\section{FATIGUE RELIABILITY MODEL: API/WIRSCHING}

To derive an expression for reliability relative to fatigue, Wirsching $[8,14]$ used the simple lognormal format for multiplicative limit state functions. A fundamental difference between the Munse and Wirsching approaches is the use of the Weibutl and lognormal distributions, respectively, for $N$. The lognormal model is also well documented. A summary followis.

The fatigue strength coefficient $A$ is defined as a random variable describing the inherent variability of the fatigue strength. The median $A$ defines the median $S-N$ curve, and the $\operatorname{Cov}, C_{A}$, is the $\operatorname{Cov}$ of $N$ given $S$. Bias and uncertainty in Miner's rule are defined by $\Delta$, the damage index at failure; the event of faiture is $(D, \Delta)$. B was previously defined to describe stress modeling error. $\Delta, B$, and $A$ are assumed to have lognormal distributions with medians $(\tilde{\Delta}, B, A)$ and CoV's $\left(C_{\Delta}, C_{B}, C_{A}\right)$, respec-
tively.

The probability of failure is

$$
p_{f}=\Phi(-\beta),
$$

where $\Phi(\cdot)$ is the standard normal distribution function and $\beta$ is defined as the safety index,

$$
B=\frac{\ln \left(\tilde{T} / T_{S}\right)}{\sigma_{\ln T} T},
$$

where $T_{S}$ is the service life and $T$ is the median time to failure,

$$
\tilde{T}=\frac{\widetilde{\Delta R}}{\tilde{B} m_{\Omega}} \text {, }
$$

and

$$
\sigma_{\ell, n}^{2} T=\ln _{n}\left\{\left(1+c_{\Delta}^{2}\right)\left(1+c_{A}^{2}\right)\left(1+c_{B}^{2}\right)^{m^{2}}\right\} .
$$

The Murise model and the lognormal format are elementary reliability models, but more
Sophisticater approdches have been developed. For example, Madsen [29,30] employs advanceit reliability methods with a more general description of the fatigue limit state along with a more detailed and accurate description of the $S$ $N$ statistics defining fatigue strength.

\section{STATISTICAL DATA: EXAMPLES}

Examples of supporting data for the reliability models are provided in Tables II-IV. The $S-N$ fatigue data of Figure 4 are analyzed using a least squares model on a log-log basis. The relatively large Cov's associated with cycle life demonstrate the high level of uncertainty in fatigue design factors, thereby supporting the claim that reliability methods are particularly relevant for fatigue.

Exercises which have attempted to quantify stress modeling errors (the random variable $B$ ) are summarized in Table III. The figures in each example, provided by expert testimony and some data, are highly dependent upon the nature of the system and how the analysis is performed. Therefore, the figures should not be used by themselves without knowledge of relevant details. It is interesting to note, however, that there is some coherence in these numbers. Designers seem to believe (a) that there is a slight conservative bias to stress analysis and (b) that uncertainties may range from about 20 to $50 \%$, with lower figures typical of static designs.

Strength modeling error (the random variable $\Delta$ ) is measured from rardom fatigue testing. Recalise fatigue behavior is influenced by so many factors, it is difficult to interpret the meaning of each result in the summary of Table IV. These figures also contain variability inherent in the material. But, again, there seems to be some coherence to the values. A slight non-conservative bias is suggested by recent tests on welded detail, and uncertainties of 30 to $60 \%$ seem to be typical.

\section{DESIGN CONSIOERATIONS}

\section{Example 1}

Reliability assessment of a component is possible using the Munse or lognormal form (Eq. 14 and 15). These equations can also be used to establish design criteria. As an example, assume that the stress distribution is Weibull (Eq. 5-8). Using the value of $\Omega$ from Table 1 , a maximum allowable design stress $c a n$ be derived 「.3]

$$
S_{O}<S_{N} \cdot \psi \cdot R_{F},
$$

where

$$
\begin{aligned}
S_{N}=\left(\AA / N_{S}\right)^{1 / m}, & \text { mean fatigue strength } \\
& \text { at service life, } N_{S}
\end{aligned}
$$


Table II. Examples of statistical data on S-N curves.

\begin{tabular}{|c|c|c|c|}
\hline$N S m=A$ & in & $\begin{array}{l}\text { Median of } A \\
A(\mathrm{MPa} / \mathrm{ksi})\end{array}$ & $\begin{array}{c}\operatorname{cov} \text { of } N^{\star} \\
C_{N}(\%)\end{array}$ \\
\hline $\begin{array}{l}\text { WRC data from RP2A } \\
\text { (1982) commentary [10] }\end{array}$ & 4.38 & $2.16 \mathrm{E} \quad 4.60 \mathrm{E} 12$ & 73 \\
\hline API-X [14] & 4.42 & & 136 \\
\hline $\begin{array}{l}\text { Butt Welded Joints } \\
\text { Munse et al. }[3]\end{array}$ & 2.88 & $9.67 \mathrm{E} 11 / 3.72 \mathrm{Eg}$ & 50 \\
\hline \multicolumn{4}{|l|}{$\begin{array}{l}\text { UK DEn S-N curves } \\
\text { for welded joints [11] }\end{array}$} \\
\hline $\begin{array}{l}B \\
C \\
D \\
E \\
F \\
F 2 \\
G \\
W \\
T\end{array}$ & $\begin{array}{l}4.0 \\
3.5 \\
3.0 \\
3.0 \\
3.0 \\
3.0 \\
3.0 \\
3.0 \\
3.0\end{array}$ & $\begin{array}{lll}2.34 & \mathrm{E} 15 / 1.04 & \mathrm{E} 12 \\
1.08 & \mathrm{E} 14 / 1.25 & \mathrm{E} 11 \\
3.99 & \mathrm{E} 12 / 1.21 & \mathrm{E} 10 \\
3.29 & \mathrm{E} 12 / 1.00 & \mathrm{E} 10 \\
1.73 & \mathrm{E} 12 / 5.28 & \mathrm{Eg} \\
1.23 & \mathrm{E} 12 / 3.75 & \mathrm{E} 9 \\
5.66 & \mathrm{E} 11 / 1.73 & \mathrm{E} 9 \\
3.68 & \mathrm{E} 11 / 1.12 & \mathrm{E} 9 \\
4.79 & \mathrm{E} 12 / 1.46 & \mathrm{E} 10\end{array}$ & $\begin{array}{l}44 \\
50 \\
51 \\
63 \\
54 \\
56 \\
43 \\
44 \\
67\end{array}$ \\
\hline
\end{tabular}

*It is easily shown that $C_{A}=C_{N}$.

Table III. A summary of some efforts to quantify modeling error in stress analysis; the random variable $B$.

\begin{tabular}{|c|c|c|c|}
\hline Study & $\begin{array}{c}B i a s \\
(\tilde{B})\end{array}$ & $\begin{array}{l}\text { COV } \\
(\%)\end{array}$ & Comments \\
\hline $\begin{array}{l}\text { Load and resistance factor } \\
\text { design (LRFD) for onshore } \\
\text { construction [15] }\end{array}$ & -- & 24 & $\begin{array}{l}\text { Live load effects for floor } \\
\text { beams; a "small" part is } \\
\text { objective uncertainty }\end{array}$ \\
\hline $\begin{array}{l}\text { National Bureau of Standards } \\
\text { SP577 providing background } \\
\text { for ANS A58, "Building Code } \\
\text { Requirements . . ." [16] }\end{array}$ & -- & 20 & $\begin{array}{l}\text { Maximum live load for a } \\
50 \text {-year reference period }\end{array}$ \\
\hline $\begin{array}{l}\text { LRFD proposed for offshore } \\
\text { construction; Project } \\
\text { API-PRAC-22[17] }\end{array}$ & 0.70 & 37 & $\begin{array}{l}\text { Maximum design load effect } \\
\text { for fixed offshore } \\
\text { structures }\end{array}$ \\
\hline $\begin{array}{l}\text { Modeling error for extreme } \\
\text { wave loads on a pile; } \\
\text { average conditions in the } \\
\text { North Sea; NTH, } \\
\text { Trondheim [18] }\end{array}$ & -- & $34-45$ & $\begin{array}{l}\text { Using design wave approach, } \\
\text { the uncertainty on the } \\
\text { extreme life-time force } \\
\text { on a pile }\end{array}$ \\
\hline $\begin{array}{l}\text { ABS survey to establish } \\
\text { modeling error associated } \\
\text { with design loads for } \\
\text { cylinders and pontoons } \\
\text { for TLP's [19] }\end{array}$ & 0.90 & 25 & $\begin{array}{l}\text { Bias value selected by the } \\
\text { committee is more conserva- } \\
\text { tive than the } 0.70 \text { actually } \\
\text { found in the survey }\end{array}$ \\
\hline $\begin{array}{l}\text { Study of fatigue stress } \\
\text { modeling error for offshore } \\
\text { platforms by DnV [20] }\end{array}$ & 0.84 & 14 & $\begin{array}{l}\text { Cov seems low and out of } \\
\text { line with other } \\
\text { experiences }\end{array}$ \\
\hline $\begin{array}{l}\text { Study of fatigue stress } \\
\text { modeling error for offshore } \\
\text { platform; API fatigue } \\
\text { reliability project } \\
\text { API-PRAC-15 [8] }\end{array}$ & 0.70 & 50 & $\begin{array}{l}\text { A major contributor to Cov; } \\
\text { uncertainty in description } \\
\text { of sea state has strong } \\
\text { influence on fatigue } \\
\text { stresses }\end{array}$ \\
\hline $\begin{array}{l}\text { SSC }-322 \text { extreme wave and } \\
\text { whipping loads of ship } \\
\text { structures [21] }\end{array}$ & -- & $25-30$ & $\begin{array}{l}\text { These figures do not include } \\
\text { uncertainty in stress } \\
\text { calculations }\end{array}$ \\
\hline
\end{tabular}


Table IV. Examples of statistical data on danage at failure, $\Delta$.

\begin{tabular}{|c|c|c|}
\hline & $\begin{array}{l}\text { Median } \\
\quad(\Delta)\end{array}$ & $\operatorname{COV}_{\Delta}$ of \\
\hline $\begin{array}{l}\text { Shin and Lukins } 122] \text { : Survey of variable amplitude } \\
\text { fatigue data }\end{array}$ & 0.90 & 0.57 \\
\hline $\begin{aligned} \text { Schutz [23]: } & \text { Survey of random tests } \\
& \text { Large quasi-static mean load changes }\end{aligned}$ & $\begin{array}{l}1.00 \\
0.70\end{array}$ & $\begin{array}{l}0.60 \\
0.60\end{array}$ \\
\hline $\begin{array}{l}\text { Schilling et a1. [24]: Full-scale cover-plated } \\
\text { steel beams }\end{array}$ & 1.15 & 0.48 \\
\hline $\begin{array}{l}\text { Gurney [25]: Longitudinal non-load carrying } \\
\text { fillet welds }\end{array}$ & 0.85 & 0.28 \\
\hline Eide and Berge [26]: Non-load carrying fillet welds & 0.78 & 0.19 \\
\hline Berge and Eide [27]: Non-load carrying fillet welds & 1.06 & 0.40 \\
\hline Holmes and Kerr [28]: Cruciform specimen & 0.69 & 0.61 \\
\hline
\end{tabular}

$$
R_{F}= \begin{cases}{\left[\frac{P_{0} C_{N}^{-1.08}}{\Gamma\left(1+C_{N}^{1.08}\right)}\right]^{1 / m}} & \begin{array}{l}
\text { Munse reliability } \\
\text { factor }
\end{array} \\
\frac{1}{B}\left[\frac{\tilde{\Delta}}{\exp \left(\beta_{0} \sigma \ell n T\right)}\right]^{1 / m} & \begin{array}{l}
\text { lognormal relia- } \\
\text { bility factor }
\end{array}\end{cases}
$$

where $p_{0}$ and $B_{0}$ are the target $p_{f}$ and safety index, respectively, which must be specified.

Examples of the use of the Munse and lognormal formats are given in References [3] and [8]. Because of the relatively "strong" left tail of the Weibull distribution for $N$, design stress ranges $S_{0}$ of the Munse criterion are smaller than those of the lognormal format and, sometimes, much more so. A study of the distribution of fatigue data in welded joints has indicated the lognormal to be generally a better model for $\mathrm{N}$ than the Weibull [31]. But it would be premature to suggest that the lognormal format provides improved design criteria.

\section{Example 2}

Frequently, design criteria documents specify a maximum allowable damage at failure defined as a target damage ratio, $\Delta_{0}$. A restatement of the form of the lognormal approach can produce a $\Delta_{0}$ having a probability basis [40].

Noting from Eq. 5 that median damage at service life TS is

$$
\tilde{D}=\frac{T_{S} \tilde{B}_{\Omega}}{\tilde{A}},
$$

it follows from Eq. 16 and 17 that.

$$
\beta=\frac{\ln (\tilde{\Delta} / \tilde{D})}{\sigma_{\ln T}} .
$$

Requiring that $\beta>\beta_{0}$, the target safety index, the requirement for a safe design can be written as

$$
\tilde{D}<\frac{\tilde{\Delta}}{\exp \left(\beta_{0} \sigma\right)}
$$

To develop a convenient design equation, consider a factored form of $\tilde{D}$. Let the design $S-N$ curve be a lower bound specified by $A_{0}$, aS shown in Figure 7. Define the scatter factor

$$
\lambda=\tilde{A} / A_{0} \text {. }
$$

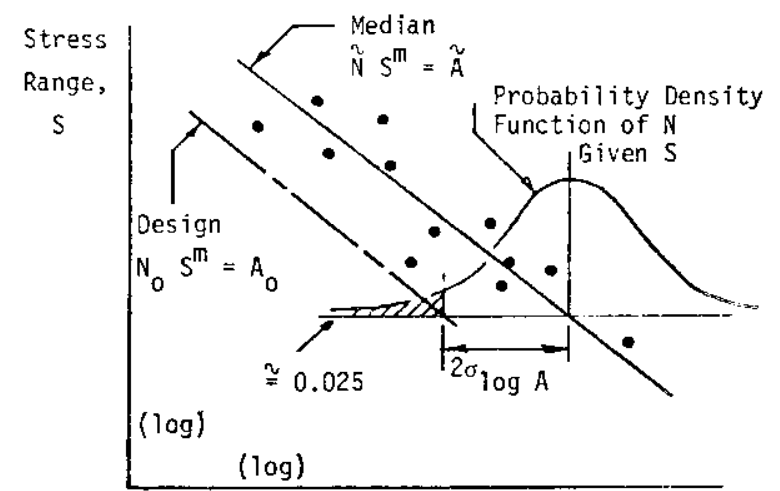

Cycles to Failure, $\mathbb{N}$

Fig. 7 Definition of the $S-N$ design curve

The relationship between $\lambda$ and the coefficient of variation of cycle life is given as

$$
\lambda=\exp \left(2 \sigma_{\ell, n}\right) \text {, }
$$

where 


$$
\sigma_{\ln A}=\sqrt{\ln \left(\overline{1}+C_{A}^{2}\right)}
$$

From Eq. 23 and 24 ,

$$
\tilde{\mathrm{D}}=\left(\mathrm{B}^{\mathrm{BH}} / \lambda\right) \mathrm{D}_{\mathrm{O}}
$$

where

$$
D_{0}=T_{S \Omega} / A_{0}
$$

$\mathrm{D}_{0}$ is nominal damage (damage as would be computed by conventional design procedures). Finally, the safety check expression can be derived from Eq. 23-28 as

$$
D_{0}<\Delta_{0},
$$

where the target damage ratio $\Delta_{0}$ is

$$
\Delta_{0}=\frac{\lambda \tilde{\Delta}}{\beta^{m} \cdot \exp \left(\beta_{0} \sigma\right)} .
$$

As an example, consider the statistics in Table $V$. These values were assumed to be "reasonable" for development of ILP design criteria [32]. Upon substitution into Eq. 30, a plot of $\Delta_{0}$ versus $B_{0}$ can be constructed as shown in Figure 8. Upon selection of an appropriate target safety iridex $\beta_{0}$, the value of $\Delta_{0}$ can be established. An example of design criteria for deck and hull structural detail for TLP's is given in Table VI. Selection of $\beta_{0}$ is influenced by considerations of importance and inspectability.

ELEMENTARY CONSIDERATIONS OF SYSTEM RELIABILITY ANALYSIS: TLP TENDONS

Ulimately, it is hoped that technology will be available to perform (a) reliability assessments of a systeni of components or (b) given the target reliability of a system, derive component requirements. In general, the system reliability probiem is extremely complex [33, $34,35]$. Stahl and Geyer $[36,37]$ have

\begin{tabular}{|c|c|}
\hline$m$ & 3.0 \\
\hline$C_{A}{ }^{*}$ & 0.50 \\
\hline$\Delta$ & 1.0 \\
\hline$c_{\Delta}$ & 0.30 \\
\hline$\tilde{B}$ & 0.90 \\
\hline$c_{B}$ & 0.25 \\
\hline
\end{tabular}
addressed the tendon system reliability problem considering both uitimate strength and fatigue.
Table V. Reference data for calculation of target safety index $[40]$.

${ }^{\star}$ Equal to $C_{\mathbb{N}}$, the cov of cycles to failure.

Design Life, $T_{0}$, for a Service Life, $T_{S}$, of $20 \mathrm{Yrs}$.

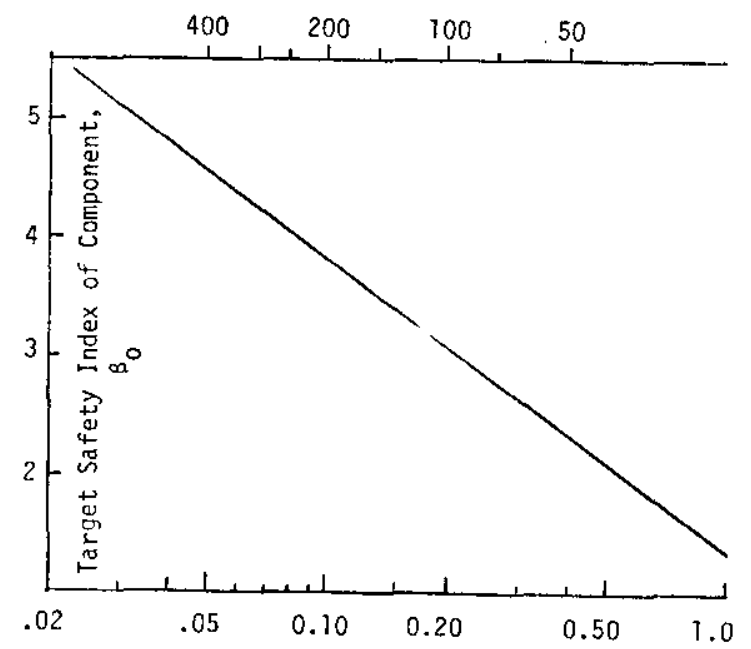

Target Damage Level for Component, $\Delta_{0}$

Fig. 8 Example: The target safety index as a function of the target damage level for a component

Table VI. Example: Fatigue design criteria for TLP deck and hull structure.

$\begin{array}{ll}\begin{array}{l}\text { Target Safety } \\ \text { Index, } B_{0}\end{array} & \begin{array}{l}\text { The structure is redundant and cracks } \\ \text { are easily inspected and repaired; } \\ \text { used for deck structure, mating joints, } \\ \text { main body of cylinders and pontoons, } \\ \text { and production risers }\end{array} \\ 2.0 & \begin{array}{l}\text { For redundant and non-critical } \\ \text { structure which is non-inspectable, } \\ \text { i.e., non-inspectable deck structure }\end{array} \\ & \begin{array}{l}\text { The structure is critical and, while } \\ \text { inspection is possible, repairs are } \\ \text { expensive; used for pontoon/ } \\ \text { cylinder interface, main braces, } \\ \text { and for tension pile pullout }\end{array}\end{array}$


In the example which follows (a summary of [40]), TLP tendon fatigue design criteria are Jerived basod on a host of simplifying assumptions.

4 :- $P$ tendon model is shown in figure 9. It is assuined that (1) each tendon has $n$ "components" or fatigue-sensitive points, (2) the axial force throughout the tendon is uniform, (3) fatigue will be the principal failure mode, (4) stress corrosion effects are ignored, and (5) there is no effective inspection program.

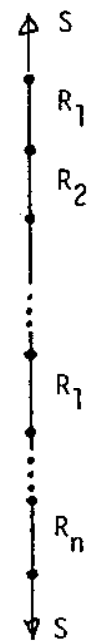

Fig. 9 Model of a TLP tendon

Let $S$ denote the stress in a tendon and $R_{j}$ denote the strength of the $i_{\text {th }}$ element. The event of failure of the $i_{\text {th }}$ component is

$$
E_{i}=\left(R_{i}<S\right) \text {. }
$$

The probability of failure of the $i^{\text {th }}$ component is

$$
\mathrm{p}_{i}=P\left(R_{i}<S\right) \text {. }
$$

The tendon then is a simple series system of $\mathrm{m}$ components. If $E_{j}$ were assumed to be independent, an upper bound on the probability of tendon failure is [33]

$$
\mathrm{p}_{\mathrm{T}}<n \mathrm{p}_{\mathrm{i}}
$$

The exact probability of tendon failure

where

$$
p_{T}=\int_{0}^{\infty} f_{S}(x) F_{R}(x) d x,
$$

$$
F_{R}(x)=1-\left[1-F_{R_{j}}(x)\right] n \text {. }
$$

$F_{R_{j}}$ and $F_{R}$ are the distributions of component and tendon strength, respectively.

For fatigue, it is shown in Reference [38], using the lognormal format, that

$$
S=B_{S} S e / \Delta^{1 / m}
$$

$$
P_{i}=\frac{\left(A / N_{S}\right)^{l / m}}{B_{C, i}}
$$

where stress modeling error $B$ is separated into components $B S$ for the structure as a whole and $\mathrm{B}_{\mathrm{c}, \mathrm{i}}$ for error which varies from component to component. Characteristic statistics based on typical values are $C_{R_{i}}=0.20$ and $C_{S}=0.23$ [38].

Using these values, the relationship between component and system probability of failure is illustrated in Figure 10 for both the dependent failure mode case (Eq. 35) and the upper bound (Eq. 33). The safety index is related to $p_{f}$ by Eq. 15.

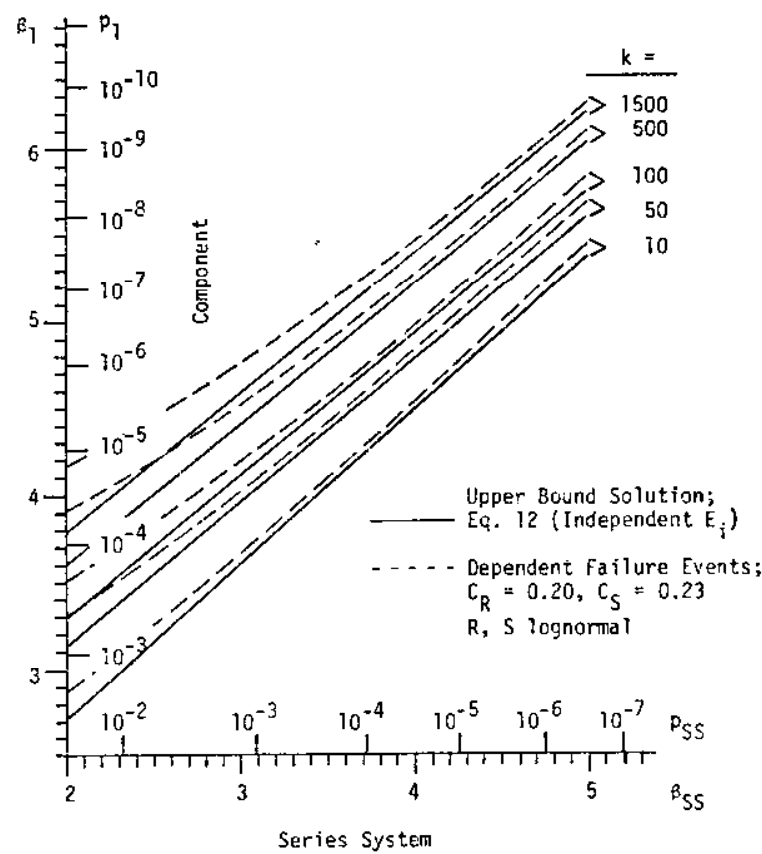

Fig. 10 Component reliability as a function of series system reliability; $k$ elements

Using these results, Eq. 30, and the values in Table $V$, the target damage level $\Delta_{0}$ can be derived as a function of the specified target safety index for a tendon $B T$ and the number of joints. Superimposed on the results (both the upper bound and dependent case) presented in Figure 11 is the recommendation of $\Delta_{0}=0.10$ by the API Tendon Systems Design Task Group.

Conclusions from the exercise are that (1) $\Delta_{0}$ is not a strong function of the number of components and (2) the upper bound solution produces only slightly conservative requirements.

Finally, it should be noted that specified target reliabilities relate to service lives. When, for example, the target tendon reliability is specified as $B T=3.0$, this value applies at time $t=T_{S}$. For all $t<T_{S}$ during the service life, the actual reliability will exceed 3.0 .

By direct application of the lognormal format described earlier, component reliability 


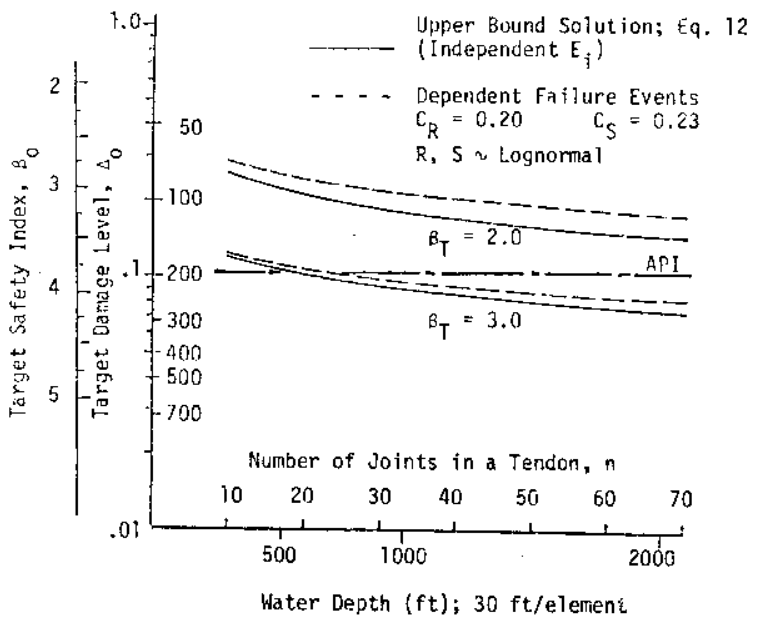

Fig. 11 Target fatigue damage level as a function of number of joints in tendon

$B_{1}$ for any time can be formulated as

$$
\beta_{3}(t)=\beta_{0}-\frac{\ln \left(t / T_{S}\right)}{\sigma_{\ln T}},
$$

where $\sigma_{0 n T}$ is given by Eq. 18. For the values in Table $f_{,} T=0.925$. The relationship between riskn and operating time of Eq. 38 is presented in Figure 12 for this value. This figure illustrates a rather dramatic degradation in structural integrity due to "aging." It also suggests conservatism in the way fatigue requirements are constructued; i.e., when reliability specifications are targeted to the service life, a higher reliability is realized during operation.

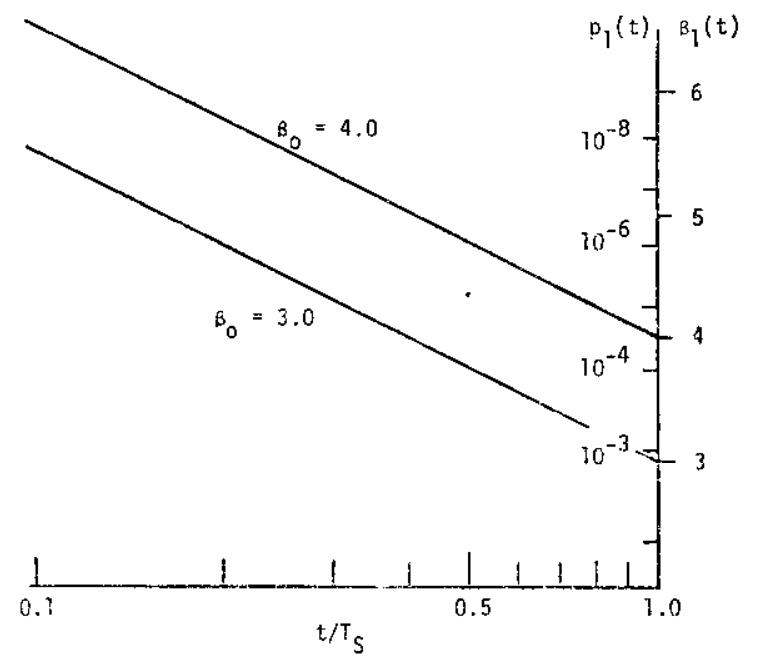

Fig. 12 Degradation in reliability as a function of time

\section{CONCLUSIONS}

Reliability mathematics can be useful as a tool for managing the Targe uncertainties asso- ciated with fatigue, thereby providing designers with a sound basis for decision making. Summarized in this paper are elementary methods of reliability assessment and design code development relative to fatigue. Research efforts continue worldwide on this important topic.

\section{ACKNOWLEDGMENTS}

Many of the results presented here are based on studies supported earlier by the American Petroleum Institute with Bernhard Stahl as the project technical advisory committee chairman and, more recently, by the American Bureau of Shipping, Research and Development Division, of which Don Liu is director. All results presented herein have not been formally reviewed and approved for use by ABS. Permission by ABS to present and publish this work is gratefully acknow ledged.

\section{REFERENCES}

1. Almar-Ness, A. (Ed.), Fatigue Handbook: Offshore Steel Structures, Trondheim, Norway, Tapir Publishers, 1985.

2. Design of Tubular Joints for offshore Structures (3 volumes), UEG Fulication UR33, UEG/CIRIA, 1985.

3. Munse, W. H., Wilbur, T. W., Tellalian, M. L., Nicoll, K., and Wilson, K., "Fatigue Characterization of Fabricated Ship Details for Design," SSC-318, U.S. Coast Guard, Aug. 1982.

4. Burnside, 0. H., Hudak, S. J., Delkers, E., Chan, K., and Dexter, R. J., "Long Term Corrosion Fatigue of Welded Marine Steels," SSC-326, U.S. Coast Guard, March 1984.

5. Marshall, P. W. and Luyties, W. H., "Allowable Stress for Fatigue Design," Paper presented at BOSS '82, Boston, Mass., Aug. 1982.

6. Gurney, T. R., Fatigue of Welded Structures, 2nd Ed., New York, Cambridge Univ. Press, 1979.

7. Wirsching, P. H., Ortiz, K., and Chen, Y. N., "Fracture Mechanics Fatigue Model in a Reliability Format," Proceedings, 6th International Symposium on Offshore Mechanics and Arctic Engineering, 1987.

8. Wirsching, P. H., "Fatigue Reliability for Offshore Structures," ASCE Journal of Structural Engineering, October, 1984.

9. Wirsching, P. H., "Fatigue Damage Assessment Models for Offshore Structures," Earthquake Behavior and Safety of Oil and Gas Storage Facilities, New York, Amer. Soc. Mech. Eng., 1983.

10. API Recommended Practice for Planning, Designing, and constructing Fixed offshore Platforms, $13 \mathrm{th}$ Ed., RP2A, API, $19 \overline{8} \overline{2}$. 
$\because \because \because=$ installations: Guidance on Design -- znstruction; Proposed New Fatigue Es-ar zjies for Steel Welded Joints in "znore Structures," AERE Harwell, Oxfordsmire, dune 1981.

i2. Wirsching, P. H., "A General Expression for Fatigue Damage Under Weibull Distributed Stresses and Bilinear S-N Curves," Report No. 24 to ABS, Nov. 1985.

13. Ang, A. H-S., "Bases for Reliability Approach to Structural Fatigue," Proceedings, 2nd Internationa! Conference on Structural Safety and Reliability, 1977.

14. Wirsching, P. H., "Probability Based Fatigue Design Criteria for offshore Structures," Fina? Report API-PRAC-15, American Petroleum Institute, Jan. 1985.

15. Ravindra, M. K. and Galambos, T. V., "Load and Resistance Factor Design for Steel," ASCE, Journal of the Structural Division, September, 1978.

16. Ellingwood, B., Galambos, T. V., MacGregor, J. G., and Cornell, C. A., "Development of a Probability Based Load Criterion for American Standard A58," NSS Special Publication $577,1980$.

17. Moses, F., "Development of Preliminary Load and Resistance Factor Design Document for Fixed Offshore Platforms," Final Report API PRAC 85-22, American Petroleum Institute, 1986.

18. Soares, C. G. and Moan, T., "On the Uncertainties Related to the Extreme Hydrodynamic Loading of a Cylindrical Pile," Reliability Theory and Its Application in Structural and Soil Mechanics, The Hague, Netherlands, Martinus Nijhoff Pub1., 1982.

19. "Final Report: Questionnaire on Non-Statistical Uncertainties in Design Loads for Tension Leg Platforms," American Bureau of Shipping, unpubtished study, 1982.

20. Gran, S., "Fatigue and Crack Failure Prediction Methods in Marine Structures," Technical Report 80-0688, Det Norske Veritas, 0slo, Norway, May 1980.

21. Kaplan, P., Benatar, M., Bentson, J., and Achtarides, T. A., "Analysis and Assessment of Major Uncertainties Associated With Ship Hull UTtimate Failure," SSC-322, U.S. Coast Guard, 1984.

22. Shin, Y. S. and Lukens, R. W., "Probability Based High Cycle Fatigue Life Predictions," Random Fatigue Life Prediction, New York, Amer. Soc. Mech. Eng., 1983.

23. Schutz, w., "The Prediction of Fatigue Life in the crack Initiation and Propagation Stages--A State of the Art Survey," Engineering Fracture Mechanics, Vol. 11, No. 2, 1979 .
24. Schilling, C. G., Klippstein, K. H., Barsoin, J., and Blake, G. T., "Fatigue of Welded Steel Bridge Members Under Variable-Amplitude Loadings," Research Results Digest No. 60, Highway Research Board, April 1974.

25. Gurney, T. R., "Fatigue Tests Under Variable Amplitude Loading," Report No. 220/83, The Welding Institute, Cambridge, United Kingdom, July 1983.

26. Eide, 0. I. and Berge, S., "Cumulative Damage of Longitudinal Non-Load Carrying Fillet Welds," to be published, International Journal of Fatigue.

27. Berge, S. and Eide, D. I., "Residual Stress and Stress Interaction in Fatigue Testing of Welded Joints," Norwegian Institute of Technology, Trondheim, 1981.

28. Holmes, R. and Kerr, J., "Fatigue Strength of Welded Connections Subjected to North Sea Environmental and Random Load Conditions," Proceedings, 3rd International Conference on Behavior of offshore Structures, Vol. 2, BOSS, 1982.

29. Madsen, H. 0., Skjong, R., and MoghtaderiZadeh, M., "Experience on Probabilistic Fatigue Analysis of Offshore Structures," Proceedings, 5 th International Symposium on offshore Mechanics and Arctic Engineering, 1986.

30. Madsen, H. 0., "Bayesian Fatigue Life Prediction," in Probabilistic Methods in the Mechanics of Solids and Structures, Berlin, Springer-Verlag, 1985.

31. Wirsching, P. H., "The Statistical Distribution of Cycles to Failure .. Weibull vs. Lognormal," Report No. 17, ABS, 1984.

32. Wirsching, P. H., "Code Statement: Tension Leg Platform Fatigue Design Requirements," Vol 2, Final Report, American Bureau of Shipping, 1985.

33. Ang, A. H. S. and Tang, W. H., Probability Concepts in Engineering Planning and Design, VoT. 2, New York, John Wiley \& Sons, 1984.

34. Guenard, Y., "Application of System Reliability Concepts to offshore Structures," Ph.D. Dissertation, Stanford Univ., 1984.

35. Thoft-Christensen, $P$. and Murotsu, $Y_{.}$, Application of Structural Systems Reliability, New York, Springer-Verlag, $198 \overline{6}$.

36. Stah1, B. and Geyer, J. F., "Ultimate Strength Reliability of Tension Leg Platform Tendon Systems," OTC 4857, Offshore Technology Conference, 1985.

37. Stah1, B. and Geyer, J. F., "Fatigue Reliability of Parallel Member Systems," ASCE, Journal of Structural Engineering, October, 1984. 
38. Wirsching, P. H., "Probability Based Fatigue Design Criteria for TLP Tendons," Proceedings, 5 th International Symposium on offshore Mechanics and Arctic Engineering, 1986.

39. Nolte, K. G. and Hansford, J. E., "Closed Form Expressions for Determining Fatigue
Damage Due to Ocean Values," OTC 2606, Proceedings, Offshore Technology Conference, 1976.

40. Wirsching, P. H. and Chen, Y. N., "Fatigue Design Criteria for TLP Tendons," to be published in Journal of the Structura] Division, ASCE. 